time of the present study were regarded clinically as disease-free. All had normal urinary C.E.A. values (Table I) but six had minimally raised plasma values (Table IV). The future progress of these patients is being carefully followed, as these results may suggest the presence of local tumour undetected by cystoscopy and cytology or occult metastatic disease.

\section{Discussion}

This is the first time thai C.E.A. or C.E.A.-like material has been demonstrated in the urine of normal subjects and of patients with urothelial carcinomas. Its presence in urine is not too surprising in view of the common endodermal origin of the urinary bladder and gastrointestinal tract from which latter site and whose tumours C.E.A. was first isolated and thought to be "endodermal specific" (Gold and Freedman, 1965). Previous studies have shown that C.E.A. occurs in the plasma and faeces of healthy persons (LoGerfo et al., 1971; Moore et al., 1971; Freed and Taylor, 1972; Laurence et al., 1972) and is raised in association with a variety of malignant tumours and disorders associated with regeneration or inflammation or both (LoGerfo et al., 1971, 1972; Moore et al., 1971; Laurence et al., 1972; Reynoso et al., 1972; Zamchek et al., 1972).

From the results of the present series of urinary C.E.A. assays almost $70 \%(26 / 38)$ of subjects with active bladder carcinomas will be found to have raised levels, while normal levels occur in patients who have had successful removal of the tumour (Table I). In contrast to plasma C.E.A. levels which seem to be raised, particularly after local spread of all types of tumours, high urinary C.E.A. levels occurred in 7 out of 15 examples of $\mathrm{T} 1$ bladder carcinomas-that is, showing in-situ or early invasive tumours. Consequently, the assay of urinary C.E.A. appears to be clinically useful in the investigation of patients suspected of having urothelial carcinomas, possibly for the screening of the growing "high-risk" population in certain industries and for the detection of persistent or recurrent carcinoma after appropriate treatment.

In this respect, although assay of plasma C.E.A. levels has little to add in the early stages of carcinoma of the bladder, and does not seem to correlate with urinary levels, C.E.A. measure- ments in plasma and urine are both desirable in the follow-up phases, as plasma values may be raised in the presence of normal urinary levels and so possibly indicate extravesical spread. The more valuable role of urinary C.E.A. for bladder tumours probably is related to the fact that the urine is the immediate environment of the bladder mucosa and its papillary carcinomas. Certainly C.E.A. does not appear in the urine with most non-urothelial tumours even when the plasma level is raised unless such tumours involve the urothelium secondarily or increase the risk of cervical or vaginal contamination.

The possibility of contamination with genital tract secretions in females or in either sex with active urine infection must be borne in mind and excluded before any interpretation of C.E.A. data is made. Both factors can be largely eliminated by routine use of a midstream specimen of urine and its examination for cells and organisms if urinary infection is suspected.

Consequently we conclude from this preliminary data that the estimation of urinary C.E.A. or C.E.A.-like materials represents a further valuable application of this immunoassay in the diagnosis and care of patients suspected of having or with urothelial carcinomas.

We wish to express our gratitude to Professor T. Symington and Mr. David Wallace for their encouragement, and to the many clinicians who allowed patients to be studied in detail. These investigations were supported by the Medical Research Council (Grants 970/656/B and 971/817/B). One of us (R.R.H.) was in receipt of a Gordon Jacobs Research Fellowship.

\section{References}

Freed, D. L. J., and Taylor, G. (1972). British Medical fournal, 1, 85. Gold, P., and Freedman, S. O. (1965). Fournal of Experimental Medicine, 121, 439.

Laurence, D. J. R., et al. (1972). British Medical fournal, same issue

LoGerfo, P., Krupey, J., and Hansen, H. J. (1971). New England fournal of Medicine, 285 , 138 .

LoGerfo, P., LoGerfo, F., Herter, F., Barker, H. G., and Hansen, H. J. (1972). American fournal of Surgery, 123, 127.

Moore, T. L., Kupchik, H. Z., Marcon, N., and Zamchek, N. (1971). American fournal of Digestive Diseases, 16, 1.

Reynoso, G., et al. (1972). Fournal of the American Medical Association, 220, 361.

Zamchek, N., Moore, T. L., Dhar, P., and Kupchik, H. Z. (1972). New England fournal of Medicine, 286, 83.

\title{
Interactions of Benzodiazepines with Warfarin
}

\section{ORME, A. BRECKENRIDGE, R. V. BROOKS}

\section{Summary}

Administration of nitrazepam (10 $\mathrm{mg}$ nightly), diazepam (15 mg/day), and chlordiazepoxide (15 and $30 \mathrm{mg} / \mathrm{day}$ ) had no effect on steady-state plasma warfarin concentrations, the plasma half-life of warfarin, or anticoagulant control in patients and it appears safe to prescribe these agents to patients on long-term oral anticoagulants. Urinary excretion of $6 \beta$-hydroxycortisol, however, increased in two out of five patients given chlordiazepoxide. In rats

M.R.C. Clinical Pharmacology Research Group and Department of Clinical Pharmacology, Royal Postgraduate Medical School, London W.12

M. ORME, M.B., M.R.C.P., Honorary Senior Registrar

A. BRECKENRIDGE, M.B., M.R.C.P., Lecturer

Department of Chemical Pathology, St. Thomas's Hospital, London S.E.1

R. V. BROOKS, PH.D., D.SC., Reader in Chemical Pathology

pretreatment with chlordiazepoxide $(40 \mathrm{mg} / \mathrm{kg}$ for four days) caused stimulation of liver microsomal enzyme activity but neither diazepam nor nitrazepam had this effect.

\section{Introduction}

The subject of drug interactions has become very familiar to practising physicians. While a synergistic effect between drugs is widely used in therapeutics more stress is put on the adverse effects of multiple prescribing. This aspect has been widely studied in patients on long-term treatment with oral anticoagulants because such patients are frequently given other agents as part of their treatment and also because both the pharmacological effect and the plasma concentration of the oral anticoagulant can be measured, thus allowing the mechanisms of the interaction to be determined. Pronounced alteration of anticoagulant control in such patients is of obvious clinical importance. 
As part of a study to identify hypnotic and sedative drugs which might safely be prescribed to patients on long-term treatment with warfarin we have investigated the effects of administering three benzodiazepines-nitrazepam, diazepam, and chlordiazepoxide - on plasma warfarin concentration and anticoagulant control. The ability of these drugs to alter the rate of drug metabolism in rats has also been investigated since data obtained in animals are frequently extrapolated to man, and the present paper indicates some problems associated with this practice.

\section{Present Series}

Patients.-Twelve patients were investigated (10 men and two women aged 32-65 years). Seven were being treated with warfarin because of deep-vein thrombosis, three had rheumatic heart disease with atrial fibrillation, one had a cardiomyopathy, and one had complete heart block with an indwelling pacemaker. Eight of the 12 patients were not on drugs other than warfarin, while four were taking digoxin, two of whom were also taking hydrochlorothiazide. We have previously shown that concurrent administration of digoxin and hydrochlorothiazide to patients taking warfarin has no effect on the plasma warfarin concentration or on anticoagulant control (Breckenridge, Orme, Thorgeirsson, Davies, and Brooks, 1971). No patient had been on any other drug in the three months before the period of study. Consent was obtained from all patients for these investigations.

Long-term Studies.-Twelve long-term studies were carried out in which the patient's dose of warfarin was kept constant throughout the 100 days of the study. Blood samples were taken twice weekly into plastic syringes in sodium citrate. Anticoagulant control was assessed on the day of sample collection. Plasma was separated and deep frozen for estimation of plasma warfarin concentration. The first $\mathbf{3 0}$ to $\mathbf{4 0}$ days formed a control period in which good anticoagulant control was achieved and maintained in the therapeutic range (thrombotest 6-10\%). Nitrazepam $10 \mathrm{mg}$ nightly (three studies), diazepam $5 \mathrm{mg}$ three times daily (four studies), chlordiazepoxide $5 \mathrm{mg}$ three times daily (three studies), and chlordiazepoxide $10 \mathrm{mg}$ three times daily (two studies) were then given for 30 days. Measurements of anticoagulant control and of plasma warfarin concentration were made during this period and for a further $\mathbf{3 0}$ to $\mathbf{4 0}$ days after the benzodiazepine had been stopped.

Plasma Half-life of Warfarin.-The plasma half-life of warfarin was measured in three patients before starting benzodiazepine therapy and during the last week of the 30-day benzodiazepine administration. The benzodiazepines studied were diazepam (one patient) and chlordiazepoxide $10 \mathrm{mg}$ three times daily (two patients). Before the initial measurement each patient had been taking warfarin for at least 30 days before it was stopped for a 72-hour period. During this period six blood samples were taken and the plasma half-life of warfarin was calculated by a least squares method with the use of a computer program which gave $95 \%$ confidence limits of the half-life measurement. Warfarin was then restarted, anticoagulant control achieved again, and treatment with diazepam or chlordiazepoxide given for 30 days. During the last three days of this treatment warfarin was again stopped for 72 hours and the plasma half-life measured as before.

Urinary $6 \beta$-Hydroxycortisol Excretion.-6 $\beta$-Hydroxycortisol is a polar metabolite of cortisol formed in the endoplasmic reticulum of the liver and excreted unconjugated in the urine. It has been suggested that changes in the urine excretion of this steroid can be equated with changes in the activity of the enzymes of hepatic endoplasmic reticulum (Conney, Jacobson, Schneidman, and Kuntzman, 1965). In six patients three consecutive 24-hour urine collections were made before starting diazepam (two patients) and chlordiazepoxide (four patients). After 30 days' treatment with these drugs the urine collections were repeated and $6 \beta$-hydroxycortisol was measured.

Animal Studies.-Male Wistar rats weighing $100 \mathrm{~g}$ were given nitrazepam or diazepam or chlordiazepoxide $40 \mathrm{mg} / \mathrm{kg} /$ day for four days by intraperitoneal injection. On the fifth day the following measurements were made in control and treated animals: pentobarbitone sleeping time, plasma half-life of ${ }^{14} \mathrm{C}$ pentobarbitone, zoxazolamine paralysis time, and maximal velocity ( $\mathrm{V} \max$ ) of $\mathrm{N}$-demethylation of ethylmorphine by rat liver microsomal enzymes. Details of these methods have been given elsewhere (Breckenridge, Davies, Orme, and Thorgeirsson, 1969).

\section{METHODS}

Plasma warfarin was measured by the method of Lewis, Ilnicki, and Carlstrom (1970), which is specific for warfarin. None of the benzodiazepines interfered with the measurement of warfarin. Anticoagulant control was assessed by the thrombotest method (Owren, 1959). Urine $6 \beta$-hydroxycortisol was measured as outlined by Breckenridge et al. (1971).

\section{Human Studies}

\section{LONG-TERM STUDIES}

Nitrazepam.-The administration of nitrazepam $10 \mathrm{mg}$ nightly to three patients caused no change in steady-state plasma warfarin concentration or in anticoagulant control. The mean plasma warfarin concentration and the thrombotest percentage for the 14 days before nitrazepam administration and during the last 14 days of its administration are shown in Table $I$, and the Chart gives an example.

TABLE I-Change in Plasma Warfarin and Anticoagulant Control Produced by Administration of Nitrazepam $10 \mathrm{mg}$ Nightly for 30 Days

\begin{tabular}{|c|c|c|c|c|c|}
\hline \multirow{2}{*}{\multicolumn{2}{|c|}{ Case No. }} & \multicolumn{2}{|c|}{ Plasma Warfarin $(\mu \mathrm{g} / \mathrm{ml}) \pm$ S.D. } & \multicolumn{2}{|c|}{ Thrombotest (\%) \pm S.D } \\
\hline & & Control & Drug & Control & Drug \\
\hline $\begin{array}{l}1 \\
2 \\
3\end{array}$ & $\begin{array}{l}. \\
\because .\end{array}$ & $\begin{array}{l}0.72 \pm 0.04 \\
0.78 \pm 0.05 \\
1.21 \pm 0.06\end{array}$ & $\begin{array}{l}0.85 \pm 0.07 \\
0.91 \pm 0.06 \\
1.35 \pm 0.06\end{array}$ & $\begin{array}{r}7.6 \pm 0.6 \\
7.4 \pm 0.6 \\
11.5 \pm 1.0\end{array}$ & $\begin{array}{r}6.8 \pm 0.2 \\
7.6 \pm 0.6 \\
12.7 \pm 0.8\end{array}$ \\
\hline
\end{tabular}
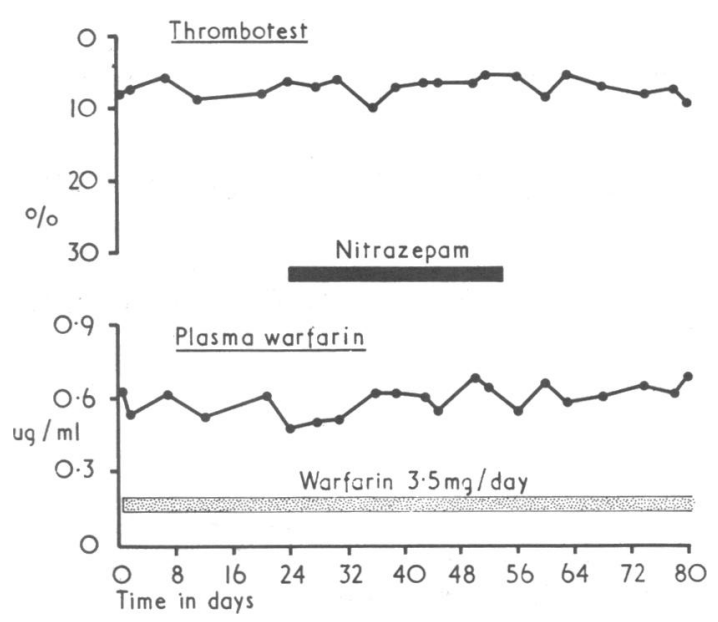

Effect in Case 1 of administration of nitrazepam $10 \mathrm{mg}$ nightly on plasma warfarin concentration and anticoagulant control.

Diazepam.-The administration of diazepam $5 \mathrm{mg}$ three times daily caused no change in the plasma warfarin concentration or in the anticoagulant control in the four patients studied. The mean plasma warfarin concentrations and thrombotest percentages before and during diazepam treatment are given in Table II.

Chlordiazepoxide.-In none of the five patients given chlordiazepoxide in a dose of either $15 \mathrm{mg}$ or $30 \mathrm{mg} /$ day was there a change in either plasma warfarin or anticoagulant control (Table III). 
TABLE II-Change in Plasma Warfarin and Anticoagulant Control Produced by Administration of Diazepam $15 \mathrm{mg}$ Daily for 30 Days

\begin{tabular}{|c|c|c|c|c|}
\hline \multirow{2}{*}{ Case No. } & \multicolumn{2}{|c|}{ Plasma Warfarin $(\mu \mathrm{g} / \mathrm{ml}) \pm$ S.D. } & \multicolumn{2}{|c|}{ Thrombotest $(\%) \pm$ S.D. } \\
\hline & Control & Drug & Control & Drug \\
\hline $\begin{array}{ll}\ldots & \ldots \\
\cdots & \ldots \\
\cdots & \cdots\end{array}$ & $\begin{array}{l}2.35 \pm 0.4 \\
2 \cdot 1 \pm 0.09 \\
0.9 \pm 0.06 \\
1.68 \pm 0.13\end{array}$ & $\begin{array}{l}2.0 \pm 0.1 \\
1.9 \pm 0.2 \\
0.8 \pm 0.15 \\
1.54 \pm 0.09\end{array}$ & $\begin{array}{l}9.0 \pm 0.4 \\
7.4 \pm 0.9 \\
6.0 \pm 0.4 \\
6.4 \pm 0.4\end{array}$ & $\begin{array}{l}10 \cdot 0 \pm 0 \cdot 6 \\
7 \cdot 3 \pm 0 \cdot 3 \\
7 \cdot 0 \pm 0 \cdot 3 \\
5 \cdot 5 \pm 0 \cdot 2\end{array}$ \\
\hline
\end{tabular}

TABle III-Change in Plasma Warfarin and Anticoagulant Control Produced by Administration of Chlordiazepoxide 15 or $30 \mathrm{mg}$ Daily for 30 Days

\begin{tabular}{|c|c|c|c|c|c|}
\hline & \multirow{2}{*}{ Case No. } & \multicolumn{2}{|c|}{ Plasma Warfarin $(\mu \mathrm{g} / \mathrm{ml}) \pm$ S.D. } & \multicolumn{2}{|c|}{ Thrombotest $(\%) \pm$ S.D. } \\
\hline & & Control & Drug & Control & Drug \\
\hline $\begin{array}{l}8 \\
9 \\
10 \\
11 * \\
12 *\end{array}$ & $\begin{array}{l}\cdots \\
\cdots \\
\cdots \\
\cdots\end{array}$ & $\begin{array}{l}0.8 \pm 0.07 \\
0.8 \pm 0.03 \\
0.66 \pm 0.06 \\
0.9 \pm 0.05 \\
3.5 \pm 0.1\end{array}$ & $\begin{array}{l}0.82 \pm 0.04 \\
0.79 \pm 0.04 \\
0.74 \pm 0.01 \\
1.1 \pm 0.03 \\
3.7 \pm 0.02\end{array}$ & $\begin{array}{l}7.4 \pm 0.4 \\
9 \pm 0.7 \\
8.6 \pm 0.8 \\
8 \cdot 1 \pm 2.0 \\
5.5 \pm 0.3\end{array}$ & $\begin{array}{c}7.6 \pm 0.2 \\
10.7 \pm 1.2 \\
11.5 \pm 0.9 \\
6.8 \pm 0.31 \\
6.1 \pm 0.5\end{array}$ \\
\hline
\end{tabular}

* Chlordiazepoxide $30 \mathrm{mg} /$ day.

\section{PLASMA WARFARIN HALF-LIFE}

The plasma warfarin half-life in Case 5 during the control period was $70.5 \pm 17$ hours and during the administration of diazepam $5 \mathrm{mg}$ three times daily it was $76.9 \pm 8.4$ hours. In case 9 before chlordiazepoxide $30 \mathrm{mg} /$ day, the plasma warfarin half-life was $29.6 \pm 6.4$ hours and during this therapy the halflife was $29 \cdot 9 \pm 5 \cdot 3$ hours. Case 10 had a control warfarin half-life of $52 \cdot 2 \pm 8 \cdot 2$ hours, and while receiving chlordiazepoxide $30 \mathrm{mg} /$ day the half-life was $47 \cdot 2 \pm 6 \cdot 7$ hours. In none of these patients, therefore, was there any change in plasma warfarin half-life during the administration of benzodiazepines.

\section{URINARY $6 \beta$-HYDROXYCORTISOL}

The administration of diazepam $15 \mathrm{mg} /$ day had no effect on the urinary excretion of $6 \beta$-hydroxycortisol in two patients. The administration of chlordiazepoxide, however, to two out of five patients caused a significant increase in steroid excretion (Table IV). It was noticeable that there was no change in plasma warfarin concentration or in anticoagulant control in either of these patients when chlordiazepoxide was administered.

TABLE IV-Effect of Diazepam (D) and Chlordiazepoxide (C.) on Urinary 6ß-hydroxycortisol Excretion

\begin{tabular}{|c|c|c|c|c|c|c|}
\hline & \multirow{2}{*}{ Case No. } & \multirow{2}{*}{ Drug } & Mean & Urinary & $\begin{array}{l}6 \beta \text {-hydroxycortisol } \\
(\mu \mathrm{g} / \text { day }) \pm \text { S.D. }\end{array}$ & \multirow{2}{*}{$\begin{array}{l}\text { Excretion } \\
\text { Drug }\end{array}$} \\
\hline & & & & Control & & \\
\hline $\begin{array}{l}7 \\
4 \\
9 \\
8 \\
12 * \\
11^{*}\end{array}$ & 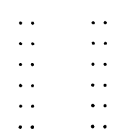 & $\begin{array}{l}\text { D. } \\
\text { D. } \\
\text { C. } \\
\text { C. } \\
\text { C. }\end{array}$ & & $\begin{array}{r}95.7 \pm 26 . \\
129.7 \pm 18 . \\
34.0 \pm 22 . \\
73.0 \pm 25 . \\
139.0 \pm 54 . \\
96.0 \pm 11 .\end{array}$ & & $\begin{array}{l}0 \pm 20 \cdot 2 \\
.0 \pm 21 \cdot 5 \\
0 \pm 34 \cdot 1 \dagger \\
.7 \pm 11 \cdot 1 \\
.8 \pm 29 \cdot 8 \\
0 \pm 100 \cdot 4 \dagger\end{array}$ \\
\hline
\end{tabular}

* Chlordiazepoxide $30 \mathrm{mg} /$ day.
† Increase significant, $\mathrm{P}<0.05$.

\section{Animal Studies}

Pentobarbitone Sleeping Time.-Animals pretreated with nitrazepam slept for $127 \cdot 3 \pm 22 \cdot 5 \mathrm{~min}$ when given pentobarbitone $30 \mathrm{mg} / \mathrm{kg}$. Diazepam-pretreated animals slept for $121 \pm 19.4 \mathrm{~min}$, while in chlordiazepoxide-pretreated animals the mean sleeping time was $15.3 \pm 6.5 \mathrm{~min}$. The mean sleeping time for control animals was $118.7 \pm 22.9 \mathrm{~min}$. Only the chlordiazepoxide-treated animals differed significantly $(P<0.05)$ from controls.

Plasma Half-life of ${ }^{14} \mathrm{C}$ Pentobarbitone. - The plasma half-life of ${ }^{14} \mathrm{C}$ pentobarbitone in control animals was $83 \cdot 1 \pm 19 \cdot 1 \mathrm{~min}$.
It was significantly shorter in chlordiazepoxide-treated animals $(27 \cdot 5 \pm 9 \cdot 2 \mathrm{~min})$ but not in nitrazepam-treated animals $(82.3 \pm$ $13.3 \mathrm{~min}$ ) or diazepam-treated animals $(105.4 \pm 27.6 \mathrm{~min})$.

Zoxazolamine Paralysis Time.-The duration of paralysis after zoxazolamine administration in control rats was $262.8 \pm$ $62.3 \mathrm{~min}$. In chlordiazepoxide-treated rats it was significantly shorter $118.5 \pm 13.4 \mathrm{~min}(\mathrm{P}<0.05)$ but not different from controls in either nitrazepam-treated rats $(202.4 \pm 79.6 \mathrm{~min})$ or diazepam-treated rats $(260 \cdot 1 \pm 67.6 \mathrm{~min})$.

Liver Microsomal Enzyme Studies.-The V max of ethylmorphine $N$-demethylation in control animals was $75 \cdot 2 \pm 4 \cdot 4$ $\mathrm{nM} / \mathrm{mg}$ protein $/ 10 \mathrm{~min}$. In chlordiazepoxide-treated animal the $V$ max was significantly $(P<0.05)$ greater at $109.3 \pm 4.6 \mathrm{nM}$, but not different from controls in rats treated with nitrazepam $(87.1 \pm 6.0 \mathrm{nM})$ or diazepam $(80.9 \pm 1.9 \mathrm{nM})$. These studies suggest that in the dose administered chlordiazepoxide stimulates the activity of rat liver microsomal enzymes, but neither nitrazepam nor diazepam have this effect.

\section{Discussion}

These studies form part of a series of investigations in man designed to find hypnotic and sedative drugs which can be given to patients on long-term warfarin therapy without altering anticoagulant control. We have previously shown that dichloralphenazone induces hepatic drug-metabolizing enzyme activity, while chloral hydrate displaces warfarin from binding on plasma albumin through its metabolite trichloroacetic acid (Breckenridge et al., 1971). Of barbiturates investigated, both amylobarbitone and quinalbarbitone increased the rate of warfarin metabolism in man (Breckenridge and Orme, 1971). The studies reported here suggest that none of the three benzodiazepines alter either steady-state plasma warfarin concentrations or anticoagulant control. Nitrazepam in a nightly dose of $10 \mathrm{mg}$ can be regarded as one of the safest hypnotics to give patients on warfarin. In rats there was no evidence that pretreatment with large doses of nitrazepam ( $40 \mathrm{mg} / \mathrm{kg} /$ day for four days) altered the activity of drug metabolizing enzymes. Similarly, diazepam altered neither warfarin metabolism in three patients studied nor drug metabolizing activity in rats.

The results with chlordiazepoxide are slightly more difficult to interpret. In doses of $15 \mathrm{mg} /$ day (three patients) or $30 \mathrm{mg} /$ day (two patients) there was no effect on either plasma warfarin concentrations or anticoagulant control. This is in keeping with the findings of Lackner and Hunt (1968), who found that administration of this agent for 14 days altered neither the anticoagulant response nor the dosage requirements of warfarin. Robinson and Sylvester (1970) showed no effect on the plasma warfarin half-life in eight volunteers given chlordiazepoxide in a mean dose of $50 \mathrm{mg} /$ day for 21 days. Neither was the rate of metabolism of another coumarin anticoagulant increased by chlordiazepoxide administration (van Dam and Overkamp, 1967). It is thus of some interest to find in two out of five patients that chlordiazepoxide caused an increase in urinary $6 \beta$-hydroxycortisol excretion, which has been advocated as a valuable indication of change in liver microsomal enzyme activity. The enzymes concerned in the formation of this metabolite of cortisol are thought to be those also concerned in drug oxidation (Conney et. al., 1965).

The cause of this inter-individual difference in cortisol metabolism when chlordiazepoxide is given is not clear. Although benzodiazepines have actions on hypothalamic pathways concerned with the secretion of trophic hormones and with autonomic function (Butler, Besser, and Steinberg, 1968), it seems most likely that the increase in urinary $6 \beta$-hydroxycortisol output noted here is due to enzyme induction, since the total urine oxogenic steroid output did not increase with chlordiazepoxide administration.

In rats chlordiazepoxide pretreatment $(40 \mathrm{mg} / \mathrm{kg} /$ day $)$ caused an increase in the activity of the enzymes of drug metabolism. It is appreciated, of course, that this dose is considerably greater 
than that given in the human studies. This effect in rats has been reported previously (Hoogland, Miya, and Bovsquet, 1966). It illustrates that great care must be taken in extrapolating the results obtained from animal screening studies of drug metabulism to man.

The importance of these studies is that it appears safe to administer these three benzodiazepines in these doses to patients on long-term warfarin therapy without encountering problems of drug interaction, which are so frequently found with other hypnotics and sedatives.

We acknowledge the help of Mrs. Wendy Watts, Mr. Larry Davies, Dr. Donald Davies, and Professor C. T. Dollery in these studies. We are grateful to Roche Pharmaceuticals for financial support, and to B.D.H. Pharmaceuticals for supplies of thrombotest reagent.

\section{References}

Breckenridge, A., Davies, D. S., Orme, M., and Thorgeirsson, S., (1969). Fournal of Physiology, 202, 15P.

Breckenridge, A., and Orme, M. (1971). Annals of the New York Academy of Sciences, 179, 421.

Breckenridge, A., Orme, M., Thorgeirsson, S., Davies, D. S., and Brooks, R. V. (1971). Clinical Science, 40, 351 .

Butler, P. W., Besser, G. M., and Steinberg, H. (1968). Fournal of Endocrinology, 40, 391.

Conney, A. H., Jacobson, M., Schneidman, K., and Kuntzman, R. (1965). Life Sciences, 4, 1091.

Dam, F. E. van, and Overkamp, M. J. H. (1967). Folia Medica Neerlandica, 10,141 .

Hoogland, D. R., Miya, T. S., and Bovsquet, W. F. (1966). Toxicology and Applied Pharmacology, 9, 116.

Lackner, H., and Hunt, V. E. (1968). American fournal of the Medical Sciences, 256, 368.

Lewis, R. J., Ilnicki, L. P., and Carlstrom, M. (1970). Biochemical Medicine,

Owren, P. A. (1959). Lancet, 2, 754

Robinson, D. S., and Sylvester, D. (1970). Annals of Internal Medicine, 72, 853 .

\title{
Factors Leading to Dependence on Hypnotic Drugs
}

\author{
A. D. CLIFT
}

British Medical fournal, 1972, 3, 614-617

\section{Summary}

Patients in general practice complaining of insomnia of recent origin have been studied in order to ascertain which factors may be of value in the detection of those more susceptible to drug dependence. The type of sleep disturbance was found to be of importance and a personal disturbance scale was found useful as a screening test in two-thirds of the patients. No difference was found in the development of dependence on amylobarbitone and nitrazepam. One of the most important factors in the prevention of drug dependence seems to be frequent review by the doctor after the first prescription and his cautionary advice to the patient.

\section{Introduction}

Barbiturate dependence of varying severity has been known for many years since the account of Clarke (1904). Physical dependence with major withdrawal symptoms was described experimentally by Isbell (1950) in the U.S.A. and recognized clinically by Wulff (1959) in Denmark. Isbell et al. (1950) and Essig (1967) showed that a daily dose of at least $400 \mathrm{mg}$ of a barbiturate is necessary to produce a clinically significant abstinence syndrome when the drug is withdrawn.

Many patients taking barbiturate and other hypnotics regularly in small dosage never show clinical evidence of physical dependence (Johnson and Clift, 1968) and, as stressed by Tatum and Seevers (1931), psychological factors are basic in drug dependence. Drug dependence has been described as a desire to take the drug in order to experience its psychic effects (Expert Committee on Drug Dependence, 1969). It has been pointed out (Seevers and Deneau, 1964) that a need exists to determine the characteristics of individuals likely to develop drug dependence.

Prescribing patterns of psychotropic drugs in general practice were reviewed by Parish (1971), who noted the rapid rise in

the use of nitrazepam. Glatt (1969) maintained that no case of definite psychological or physical dependence on this drug had come to light, and in a review of psychotropic drugs Dally (1970) stated that "addiction to nitrazepam does not occur." The large number of prescriptions for hypnotic drugs in the National Health Service (18.8 million in 1970; Department of Health and Social Security, 1972), of which an increasing proportion are for non-barbiturate hypnotics, suggested that a prospective study of patients taking hypnotic drugs might give answers to three questions. (1) Do the non-barbiturate hypnotic drugs as represented by nitrazepam give rise to dependence, and if so is this as likely to occur as with amylobarbitone ?; (2) Are there measurable social, demographic, psychological, or personality-type characteristics which distinguish subjects who develop hypnotic drug dependence from those who do not ?; (3) Is nitrazepam as acceptable as amylobarbitone to patients with insomnia?

\section{Present Study}

The patients came from a three-handed general practice in a mainly urban and industrial area of south-east Lancashire. Only patients over the age of 15 years were included from a total list of 7,600 , the population at risk being then 5,760 .

Two groups of patients were studied; the findings in the first suggesting more detailed examination of the second. Patients were not admitted to either group unless other methods of treating their insomnia had seemed inadequate-for example, analgesics for pain-and the patient still demanded hypnotic drugs.

\section{GROUP 1}

Fifty patients presenting consecutively with a recent complaint of insomnia were prescribed a non-barbiturate hypnotic drug by one of the doctors; 43 received nitrazepam, 4 diazepam, and 3 glutethimide. They were not given any special advice about drug dependence and received repeat prescriptions as they felt they required them. Cases were reviewed by me at six months and one year. 